work for pathologists and a working manual for postmortem room technicians who are, or intend to become proper technicians, rather than confining themselves to the duties usually considered appropriate for mortuary porters. Like all the Wolfe Atlases, this one is excellent value for money and should certainly be in every morbid anatomy department.

\section{A Surgeon's Management of Gangrene}

By W. Reid and J. G. Pollock. Pp. viii +230 , illustrated. Pitman Medical, Tunbridge Wells, 1978. $£ 15.00$ (hardback).

Young surgeons in training are often surprised that their middle-aged chiefs were brought up to equate lower limb gangrene with amputation-and that usually meant through the mid-thigh. The last 3 decades have seen revolutionary changes, of which endarterectomy, bypass grafts, vascular prostheses and the Fogarty catheter have been the most important. To-day, at least half of the patients with gangrene entering hospital leave it on both feet, although admittedly they may be minus a few toes. Even if major amputation becomes inevitable when vascular reconstructive surgery is impossible or has failed and in spite of sympathectomy or sympathetic block, it is often possible now to preserve the knee joint with a below knee amputation, thanks to the new techniques of the long posterior flap. To-day's elderly amputee can also often look forward to improved rehabilitation and improved prostheses.

Against this background of progress, this new textbook gives an account of the practice of the Unit for Peripheral Vascular Surgery at the Glasgow Royal Infirmary and Belvidere Hospital. Its authors are to be congratulated on producing a well written monograph on the management of this all too common clinical problem. Naturally the bulk of the book is given over to arteriosclerotic disease and its surgery, but trauma, embolism, aneurysm and the less. common causes of gangrene are also dealt with and there is short section on mesenteric ischaemia. This is a book which will certainly be useful for surgeons in training to whom the clear text and good illustrations will prove a ready source of information on how to deal with the gangrenous limb.

\section{Surgical Conditions in Paediatrics}

By H. Homewood NixoN. Postgraduate Paediatric Series? General Editor, John Apley. Pp. xii +448 , illustratedes

Butterworths: London, Boston, etc. 1978. $£ 23.00$.

The period between the late 1940s up to the present time has been one of very rapid development in the art and science of paediatric surgery. The paediatric surgeon has extended hif్ activities into most of the surgical specialities to treat the surgically ill child. There can be few who have contribute more to both the art and the science than Harold Homewoo $\Phi$. Nixon. His research and clinical expertise as well as his postgraduate teaching have shown an enlightened approach? during the most formative years of paediatric surgery.

In Surgical Conditions in Paediatrics he summarizes the conditions which fall into the range of the paediatric surgeon a remarkable feat in so slim a volume, the concise summary of the conditions being augmented by selected references and recommended reading. There is no attempt to go into detaid of the surgical management of the conditions described. This book should grace the shelves of all those with a postgraduate interest in the surgical diseases of childhood. It should bet highly recommended to paediatricians of all grades. Though not a surgical manual on operative treatment it should prove useful to the general surgeon with an interest in paediatriss 